\title{
CELENZA, Christopher S. (2017). The Intellectual World of the Italian Renaissance. Cambridge University Press.
}

ERNESTO PRIANI SAISÓ

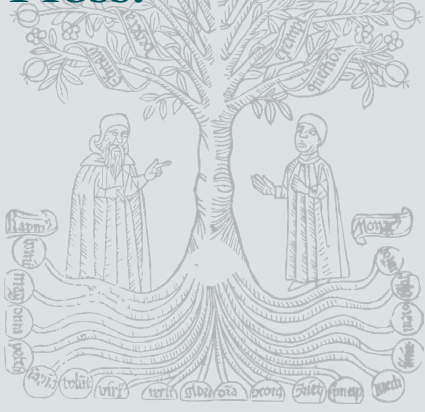

El uso y la renovación del latín y el toscano, el acceso a otras culturas a través del aprendizaje de nuevas lenguas, los problemas de la traducción, de la recepción y transformación de ideas durante el Renacimiento son los temas que aborda The Intellectual World of the Itatian Renaissance de Christopher S. Celenza. En una rápida mirada, el libro puede descomponerse en cuatro grandes secciones. Primero, la que corresponde a los grandes pensadores del siglo XIV, cuya figura central es Petrarca. En seguida, la de los humanistas de la primera mitad del siglo XV, en donde destaca Lorenzo Valla. Luego, la de los filósofos de la segunda mitad de ese mismo siglo: Ficino, Poliziano y Pico della Mirandola, y finalmente, un pensador de inicios del siglo XVI, Pietro Bembo, quien sirve como colofón a esta historia de los debates sobre el uso de la lengua, que son también debates sobre la construcción de nuevas ideas filosóficas y religiosas.

Celenza elige iniciar su recorrido en el siglo XIV porque ahí encuentra el nacimiento de las tendencias que marcaron el desarrollo posterior de esos debates. Dante, Petrarca y Boccaccio, las figuras más relevantes del siglo, son a la vez poetas que escriben en vernáculo y pensadores que escriben en latín. Según el autor, este bilingüismo define, a partir de Petrarca, el carácter de lo que se reconoce como una persona letrada. Pero el rol relevante que cobra el latín como lengua culta lleva a una ruptura con la forma de enseñanza del latín heredado de las universidades medievales, ya que con la llegada de la literatura clásica latina aparecen otros modelos de escritura y de enseñanza distintos a los escolásticos. Estos modelos no sólo se tornaron de inmediato en autoridades en el uso del latín, como Cicerón, sino que llevaron a renovar los géneros de escritura; se recuperó el tratado, por ejemplo, para romper con 
la disputa escolástica. Al tiempo que este nuevo latín se cultiva, argumenta Celenza, hay un reconocimiento del valor de la lengua vernácula como lengua materna para la expresión literaria, lo que 1levó a debates en torno a la artificialidad del latín frente a la naturalidad del toscano.

Quizás la parte más rica de todo el libro es la que corresponde a los humanistas florentinos, herederos de la cultura de Dante, Petrarca y Boccaccio, porque es entre ellos donde Celenza encuentra la mejor expresión de la imbricación entre las reflexiones sobre la lengua y la revolución del pensamiento. El libro estudia con cierto detalle a varios humanistas, como Carlucio Salutati, Leonardo Bruni, León Batista Alberti, Poggio Bracciolini y Lorenzo Valla. Entre ellos, sobresale Bruni, uno de los primeros estudiantes del griego en la Florencia renacentista y alumno de Manuel Crisoloras, con quien da inicio la discusión sobre la mejor forma de traducir del griego al latín. La llegada de otra lengua al mundo bilingüe del Renacimiento expande el debate sobre el uso de la lengua y lleva a discutir la forma en que debe ser vertido el texto en la lengua de recepción. El debate no sólo es sobre el estilo y el ritmo que se debe conservar; es también sobre cómo una filosofía, como la de los padres de la iglesia o de los autores clásicos griegos, debe trasladarse en su riqueza literaria al latín. Se trata, pues, de una filosofía que apela tanto al corazón como a la mente porque, como señala Bruni, la persuasión no es algo separado de la filosofía.

Con todo, lo más destacado de esta sección y del libro en general es el encuentro con Lorenzo Valla. Celenza logra contextualizar la importancia intelectual y personal de Valla, de quien ofrece un retrato muy rico, atendiendo a dos de sus obras más importantes: La falsa donación de Constantino, en donde debate la autenticidad de la Donación, un documento que sabemos ahora apócrifo con el que la Iglesia justificaba sus aspiraciones al poder temporal, y las críticas y comentarios a la Vulgata de san Jerónimo, en los que comparando el texto latino con el texto griego, cuestiona la versión del santo y se pronuncia por una nueva traducción de la Biblia, lo que desató un fuerte debate en torno a la autoridad para retraducir textos sagrados y la necesidad de hacer nuevas versiones con un conocimiento más profundo de la lengua.

Celenza encuentra en Valla la culminación de una posición revolucionaria que surge a partir de la transformación en el uso de dos lenguas. Al mismo tiempo, esto conduce a establecer una nueva relación con la herencia del pasado cristiano y no cristiano. En síntesis, "Al enfocarse tan intensamente en el lenguaje (no de una manera puntillosa sino, en cambio, en cómo la disposición 
de una oración ayuda a crear su sentido), la retórica representa filosofía en su más auténtico sentido" (Celenza, 2017: 194). ${ }^{1}$

Con la siguiente generación de pensadores (Ficino, Poliziano y Pico della Mirandola), Celenza no sigue el camino audaz que lo ha llevado a Valla. Su aproximación a ellos se aleja significativamente del tópico de la lengua, a pesar de la importancia que la traducción tiene en ellos y que, con Pico, el Renacimiento se abre a nuevas lenguas como el hebreo y el árabe. De hecho, reconduce su indagación a los temas más tratados sobre estos pensadores: la preocupación por la irreligiosidad y la aproximación al mundo griego de Ficino, la concordancia en Pico. Como a lo largo de todo el libro, esta sección contiene valiosa información sobre personajes menos notables y discusiones menos centrales, que por supuesto enriquecen nuestra visión sobre los debates en el Renacimiento, como es el caso de los ataques que Pulci hace constantemente a Ficino, los cuales constituyen una parte importante de la construcción de la cultura en una época en la que se buscaba todo el tiempo el favor del mecenas.

El libro retoma su hilo principal al analizar el debate entre Poliziano y Cortesi sobre el uso del latín como instrumento de cultura pública y su uso como medio de expresión propia. Una vez más resurge la dificultad de utilizar una lengua artificial, no aprendida en el seno materno, para expresar los sentimientos personales, y la cuestión de qué lengua es superior para escribir tanto la poesía como el pensamiento. Cierra el libro con la figura de Pietro Bembo, considerado el padre del italiano moderno y con quien inicia la codificación de la lengua vernácula. Se termina así en el polo opuesto del debate inicial, pero que es, al mismo tiempo, la conclusión de todos los debates: la sistematización de la propia lengua para construir con ella una nueva lengua formal y una nueva manera de expresar tanto el pensamiento como los sentimientos.

E1 mayor mérito de The Intellectual World of the Italian Renaissance es colocar a las lenguas en el centro de los debates renacentistas. Ésta es una reflexión que invita no sólo a entender el pensamiento renacentista desde otra óptica, sino también a repensar lo que significan hoy en día, como en cualquier otro momento, las lenguas para la producción del pensamiento.

\footnotetext{
1 "In focusing so intently on language (not in a picky way but rather on how the arrangement of an oration helps create its meaning), rhetoric represents philosophy in its most authentic sense."
} 